\title{
Entre la urgència a Fiji i la complexitat a Bonn. El lent camí per a la posada en marxa de l'Acord de París
}

\author{
MAR CAMPINS ERITJA
}

Professora titular d'universitat (acreditada a catedràtica)

Titular de la Càtedra Jean Monnet sobre Dret Ambiental de la Unió Europea de la

\author{
Universitat de Barcelona \\ mcampins@ub.edu
}

Vint-i-cinc anys després de l'adopció del Conveni marc sobre el canvi climàtic, la lluita contra aquest fenomen continua sent una prioritat en l'agenda de la comunitat internacional. Tot i això, no sembla que s'hagi produït, ni que els instruments internacionals actuals hagin propiciat encara un canvi dràstic en el comportament dels estats. De fet, l'apartat 17 de la Decisió de la COP21 que acompanyava l'Acord de París ${ }^{1}$ ja reconeixia que les contribucions nacionals presentades per les parts abans de la Cimera no permetien assolir l'objectiu de l'Acord de mantenir el límit dels $2^{\circ} \mathrm{C}$ de temperatura mitjana per sobre dels nivells preindustrials per a l'any 2100, sinó que apuntaven clarament cap a un augment de $3,5^{\circ} \mathrm{C}$. Dos anys després, l'informe que el PNUMA elabora anualment per mesurar la diferència entre el nivell d'emissions de gasos d'efecte hivernacle (GEH) que els estats s'han compromès a assolir i el nivell d'emissions necessari per no superar aquests $2^{\circ} \mathrm{C}$, conclou pel que fa a l'any 2016 que les emissions mundials de GEH continuen augmentant i que s'han doblat des de 1970, han crescut significativament des del 2000. Per assolir l'objectiu de l'Acord, el 2030 les emissions haurien de ser molt inferiors a les que es preveuen en l'escenari a què condueixen les polítiques actuals dels estats part ${ }^{2}$. Un altre informe recent del Govern dels Estats Units ${ }^{3}$, significatiu per la pervivència a aquest país de corrents negacionistes del fenomen del canvi climàtic, alerta que l'escalfament del planeta s'està duent a terme més ràpidament del que es preveu $\mathrm{i}$ ja constitueix una amenaça enorme per als Estats

\footnotetext{
${ }^{1}$ Decisió 1/CP.21, Doc. FCCC/CP/2015/10/Add.1

${ }^{2}$ UNEP, The Emissions Gap Report 2017. United Nations Environment, Programme (UNEP), Nairob', 2017, disponible en línia a <www.unenvironment.org/resources/emissions-gap-report>.

${ }^{3}$ USGCRP: Climate Science Special Report: Fourth National Climate Assessment, Volume I, U.S. Global Change Research Program, Washington, 2017, disponible en línia a $<$ https://science2017.globalchange.gov/>.
} 
Units i la resta del món. Així, adverteix de l'augment de la temperatura mitjana anual als Estats Units d ${ }^{\prime} 1^{\circ} \mathrm{C}$ durant els últims cent anys i de la presència des del punt de vista global de concentracions de $\mathrm{CO}_{2}$ a l'atmosfera que superen les $400 \mathrm{ppm}$, el creixement continuat de les quals pot portar a una concentració atmosfèrica que no s'ha experimentat en centenars de milions d'anys.

El Conveni marc sobre el canvi climàtic de 9 de maig de 1992 i el Protocol de Kyoto d'11 de desembre de $1997^{4}$ constitueixen la resposta que la comunitat internacional ha donat en els darrers anys a aquesta situació. Mitjançant aquests dos instruments, els estats part van establir un objectiu a llarg termini: estabilitzar les emissions dels GEH per prevenir interferències perilloses en el sistema climàtic. Per assolir aquest objectiu, el Conveni marc i el Protocol disposaven pels països desenvolupats l'obligació d'adoptar mesures de mitigació, limitant les emissions de GEH i disminuint la "petjada de carboni”. Pels països en desenvolupament era essencial la seva adaptació al canvi climàtic reduint la vulnerabilitat dels ecosistemes i augmentant la seva resiliència per fer front als impactes negatius. Des de 2007, els estats part s'han vist immersos en un llarg procés de negociació per a la renovació d'aquest compromís que va concloure amb l'adopció de l'Acord de París el 12 de desembre de 2015, en vigor des del 4 de novembre de 2016.

Durant aquests anys, el Conveni marc i el Protocol han generat efectes positius indiscutibles. Ara bé, també han fet palesa la dificultat del dret internacional per abordar d'una manera eficaç el doble repte de la mitigació i adaptació al canvi climàtic, i, molt especialment, la ineficàcia de mecanismes excessivament rígids quan manca la voluntat política dels estats i les condicions econòmiques globals no acompanyen. Ambdós instruments pretenien alinear els interessos nacionals dels estats part amb l'interès global del conjunt de la comunitat internacional mitjançant compromisos obligatoris $\mathrm{i}$ mecanismes estrictes de control de compliment. Tot i els esforços de la Unió Europea, aquest plantejament va fracassar en el seu objectiu d'implicar altres països desenvolupats, la participació dels quals era indispensable per assegurar-ne l'èxit. Els Estats Units mai van ratificar el Protocol i Canadà va preferir retirar-se'n a afrontar els compromisos de reducció de les emissions. Més endavant, la majoria dels països desenvolupats fora de la Unió Europea van declinar la seva participació en el segon període de compromís (2013-2020) adoptat mitjançant l'esmena del Protocol per

\footnotetext{
${ }^{4}$ Doc. FCCC/INFORMAL/84/Rev.1 i Doc. FCCC/INFORMAL/83.
} 
1'Acord de Doha de $2012^{5}$. Ans al contrari, aquests estats han preferit abordar els seus objectius de limitació de les emissions de manera unilateral, sense una negociació internacional com la que es va produir en el marc del Protocol. Pel que fa als països en desenvolupament $\mathrm{i}$ especialment les grans economies emergents com la Xina, l'Índia o el Brasil, han incrementat significativament els nivells d'emissió en els darrers anys.

A diferència dels instruments anteriors, l'Acord de París de 2015 es basa en la idea que els compromisos unilaterals i voluntaris assumits pels estats part poden ser més fàcilment assolits que els que se subscriuen en el marc de negociacions multilaterals. Parteix també d'un enfocament més operacional (managerial approach), en el qual l'articulació clara d'un interès global, el compromís i la transparència respecte a la progressió i a l'ambició dels objectius a assolir, a més de la possibilitat d'ajustar-se permanentment a les circumstàncies i a l'estat del coneixement científic, es consideren més efectius per avançar en la lluita contra el canvi climàtic. Quan falten dos anys per a l'adopció de l'Acord de París, sembla, però, que l'entusiasme que va acompanyar la Conferència de les Parts (COP) de 2015 comença a temperar-se.

Pel que fa a la participació en l'Acord de París, el fet més rellevant és probablement la comunicació de la intenció d'abandonar-lo per part dels Estats Units, notificada formalment el passat 4 d'agost de 2017 al secretari general de les Nacions Unides $^{6}$. No obstant això, el text de la comunicació deixa una porta oberta, ja que ara per ara el que preveu és que a menys que els Estats Units puguin identificar els termes adequats per a un nou compromís, presentaran la notificació formal de la seva retirada tan aviat com es pugui fer. Aquesta possibilitat es pot concretar, conforme a l'article 28 de l'Acord, en els tres anys des de la data d'entrada en vigor, el 4 de novembre de 2019. En tot cas, si es produeix, els Estats Units hauran d'esperar fins a l'any 2020 per retirarse oficialment, ja que aquesta decisió no serà efectiva fins que hagi transcorregut un any des de la data de la comunicació, coincidint justament amb l'endemà de les eleccions a la presidència nord-americana de 2020 .

Tot i això, l'anunci de la retirada dels Estats Units ja ha introduït un element destorbador a les negociacions en el marc de la COP 23 presidida per Fiji i celebrada a Bonn el passat mes de novembre, i ja s'han manifestat diverses posicions sobre com

\footnotetext{
${ }^{5}$ Decisió 1/CMP.8, Doc. FCCC/KP/CMP/2012/13.Add.1. Fins ara 1'han signat 95 estats, dels quals 13 estats membres de la Unió Europea al novembre de 2017, si bé l'organització encara no ho ha fet. L'esmena entrarà en vigor al cap de tres mesos del dipòsit del 144è instrument d'acceptació.

${ }^{6}$ United States of America: Communication, CN.464.2017.TREATIES-XXVII.7.d, disponible en línia a $<$ https://treaties.un.org/doc/Publication/CN/2017/CN.464.2017-Eng.pdf $>$.
} 
abordar aquesta eventualitat. Des de la Unió Europea, el comissari d'Acció Climàtica, el Sr. Arias Cañete, va suggerir al setembre que els Estats Units podrien modificar els compromisos que van assumir el 2015 i "traçar el seu propi camí"7 . Aquesta declaració va ser ràpidament contestada, d'una banda per la mateixa administració nord-americana, que va confirmar la posició inicial — que després ha matisat la delegació d'aquest país a la darrera COP de Fiji/Bonn-, i, de l'altra, per la majoria dels estats part, que s'oposen a la renegociació dels termes fixats a l'Acord i adverteixen del risc que això implica per a la seva integritat. En aquest context, un dels principals reptes polítics de la recent COP 23 ha estat, justament, preservar l'estabilitat de la coalició que va fer possible el consens sobre l'Acord de París davant les implicacions de la posició dels Estats Units.

La qüestió, doncs, és amb quin perfil afrontaran els Estats Units la seva participació a l'Acord en els propers anys, almenys mentre continuïn sent-ne part. De moment, sembla que durant tot el mandat del president Trump, els Estats Units continuaran presents en les negociacions per a l'execució de l'Acord de París i, molt particularment, continuaran vinculats per les obligacions que recullen els articles 3 i 4 relatius al compliment i al manteniment de les "contribucions determinades en l'àmbit nacional" (NDC per les sigles angleses) i a la progressió pel que fa al nivell d'ambició que han de reflectir en les NDC successives. Cap disposició de l'Acord permet matisar l'abast d'aquesta obligació ni diluir aquest compromís de les parts.

Malauradament, però, tot apunta que és força probable que aquesta posició es tradueixi en una manca de suport a les mesures de mitigació i adaptació al canvi climàtic que són indispensables per a la conservació del planeta en conjunt. De moment, com a conseqüència immediata, ha retirat la seva promesa de finançar amb dos mil milions de dòlars el Fons Verd pel Clima ${ }^{8}$. Incidirà també en els treballs d'altres fòrums multilaterals, en els quals l'acció de l'Administració nord-americana s'està orientant de nou cap a l'unilateralisme. D'altra banda, des del punt de vista intern, el president Trump ja anunciat el seu ple suport al desenvolupament del potencial energètic convencional dels Estats Units. Des d'aleshores, han anat sorgint noves coalicions en

\footnotetext{
${ }^{7}$ European Commission (Statement 17/1513)- Statement by Climate Action and Energy Commissioner Miguel Arias Cañete on the US announcement to withdraw from the Paris Agreement, 1.6.2017. Posteriorment, a la reunió ministerial sobre acció climàtica al setembre de 2017, afegia "they will not renegotiate the Paris accord, but they will try to review the terms on which they could be engaged under this agreement", a Los Angeles Time, 16/9/2017, disponible en línia a $<$ www.latimes.com/topic/business/economy/european-union-ORGOV000067-topic.html>.

8 European Parliament, Parliamentary question E-004430/2017, 6/9/2017. Answer given by Mr. Arias Cañete on behalf of the Comission, disponible en línia a $<$ http://www.europarl.europa.eu/sides/getAllAnswers.do?reference=E-2017-004430\&language=EN>.
} 
aquest país a favor de romandre dins del marc de l'Acord i complir amb els compromisos subscrits (We are Still In, US Climate Alliance, Global Covenant of Mayors for Climate \& Energy i America's Pledge, presents en la darrera COP 23 i més actius, de fet, que la delegació oficial, però amb un paper encara limitat internacionalment).

Pel que fa a la concreció dels mecanismes per assolir els objectius de l'Acord de París, les dues COP que han tingut lloc fins ara a Marràqueix i a Fiji/Bonn, han tingut un caràcter marcadament tècnic i han mostrat clarament la prevalença del pragmatisme que reflecteix l'article 2 de l'Acord, un tret directament vinculat amb la possible fragilitat d'aquest instrument internacional.

Com es sabut, l'objectiu polític principal que s'ha d'assolir en aquesta nova etapa, és el de mantenir l'augment de la temperatura mitjana mundial molt per sota de $2^{\circ} \mathrm{C}$ respecte als nivells preindustrials, i prosseguir els esforços per limitar aquest augment de la temperatura a $1,5^{\circ} \mathrm{C}$. Aquest és, en definitiva, el nivell de compromís de la comunitat internacional pel que fa al canvi climàtic. L'article 4, lluny de les expectatives de descarbonització que inicialment s'havien posat sobre la taula, es limita ara a assenyalar que les emissions totals haurien d'arribar al seu punt màxim "tan aviat com sigui possible", caure ràpidament a partir de llavors i aspirar a un "equilibri” entre les fonts i embornals de GEH en algun moment després de 2050. Una cinquantena de països ja han assolit el seu pic màxim d'emissions, mentre que d'altres s'han compromès a eliminar la combustió de carbó abans de l'any 2030.

La COP 22 de Marràqueix ${ }^{9}$ va adoptar el programa de treball anunciat a París que ha de concloure el 2018, a més de tot un seguit de decisions tècniques per al desenvolupament de l'Acord. La COP 23 de Fiji/Bonn ${ }^{10}$ no ha tingut un caràcter gaire més substantiu.

En primer lloc, el repte principal ha estat preparar-se per a l'aplicació de l'Acord en el que és el règim post-2020. Això és, fer-lo operatiu especialment pel que fa a les modalitats, institucions i processos que en garanteixen l'aplicació. En aquesta línia, s'han assolit dos resultats principals. D'una banda, s'ha prosseguit amb el programa de treball, concretant el que són "les regles del joc" pel que fa a les normes relatives als requeriments d'informació i comunicació, el marc de transparència reforçada, els esquemes de cooperació per impulsar la mitigació i les qüestions referides al

\footnotetext{
${ }^{9}$ Decisió 1/CP 22, FCCC/CP/2016/10/Add.1.

${ }^{10}$ Decisió 1/CP 23, FCCC/CP/2017/L.13.
} 
finançament. D'altra banda, també des d'un punt de vista procedimental, ha estat especialment rellevant l'establiment de l'anomenat Diàleg Talanoa, que s'iniciarà l'1 de gener de 2018. Aquest mecanisme ha de facilitar la discussió sobre el balanç de l'esforç col·lectiu de les parts en relació amb l'assoliment dels objectius de mitigació i la preparació de NDC conforme als articles 4.1 i 4.8 de l'Acord. Aquest debat s'ha de produir en la línia de pragmatisme que hem apuntat abans, en un marc que ha de ser constructiu, facilitador, orientat a solucions i que ha d'evitar la confrontació. Cal tenir present que l'any 2020, les parts hauran de comunicar les seves estratègies de reducció del nivell d'emissions de GEH a llarg termini, cosa que en principi ha de ser una oportunitat per augmentar les ambicions dels NDC dels estats abans de l'entrada en vigor de l'Acord.

En segon lloc, la COP 23 ha recordat el compliment dels compromisos per al període pre-2020, aspecte que els països en desenvolupament consideren que s'està negligint. En aquest sentit, la COP 23 ha insistit en la necessitat que les parts ratifiquin l'esmena de Doha, que encara no ha entrat en vigor i que permetrà la posada en marxa del segon període de compromís del Protocol de Kyoto. Com sol ser freqüent, les qüestions relatives al finançament també han constituït un dels principals blocs de la discussió, centrades en la participació dels països desenvolupats en el Fons d'Adaptació i la seva vinculació directa amb l'Acord de París. Cal recordar que l'article 9 de l'Acord exigeix als països desenvolupats que continuïn "encapçalant els esforços dirigits a mobilitzar finançament", però que l'apartat 115 de Decisió que l'acompanya recull només un objectiu no obligatori d'augmentar el suport financer dels països desenvolupats, "amb un full de ruta concret que porti a l'assoliment de l'objectiu de mobilitzar conjuntament 100.000 milions de dòlars anuals per a la mitigació i l'adaptació d'aquí al 2020".

Finalment, l'Acord de París fomenta la participació dels diversos actors no estatals, els quals reclamen des de fa temps senyals clars d'una voluntat política que els permeti tenir un espai en les negociacions del règim internacional del canvi climàtic. Cada vegada més presents en les sessions de la COP, aquest cop no ha estat una excepció i han assolit algun resultat significatiu. Així, la COP 23 ha adoptat un pla per avançar en la igualtat de gènere ${ }^{11}$, pendent des de la cimera de Doha, $i$ ha establert la Plataforma de Comunitats Locals i Pobles Indígenes, dissenyada a Marràqueix l'any

\footnotetext{
${ }^{11}$ Doc. FCCC/SBI/2017/L.29.
} 
passat $^{12}$, tot i reconèixer l'aportació del coneixement d'aquestes comunitats a la lluita contra el canvi climàtic. Ara bé, encara no s'han previst ni els mecanismes institucionals ni el pressupost per dur a terme aquestes iniciatives.

En aquest sentit, cal recordar que el preàmbul de l'Acord vincula l'acció contra el canvi climàtic a les exigències de justícia climàtica $i$ fa especial referència als drets humans, als pobles indígenes, les comunitats locals, els migrants, els nens, les persones amb discapacitat i les persones en situacions de vulnerabilitat, així com a la igualtat de gènere. Tot i la novetat que va representar la seva inclusió en un instrument internacional, aquesta menció té, no obstant això, un caràcter merament declaratori i queda lluny de l'establiment d'obligacions concretes per les parts.

Aquest és un dels factors que - juntament amb la manca de concreció dels compromisos de mitigació i adaptació subscrits i l'absència de mecanismes per fiscalitzar el compliment dels estats - està reforçant dia a dia el fenomen cada vegada més consolidat de la litigació ambiental que promouen aquests actors no estatals, paral·lelament a l'acció d'uns organismes internacionals sovint massa neutres quan es tracta de la responsabilitat dels estats. El 2005 el recurs de la Conferència Circumpolar Inuit contra els Estats Units davant la Cort Interamericana de Drets Humans ${ }^{13}$ es va considerar poca cosa més que una raresa. Ara, la intervenció de les jurisdiccions nacionals per resoldre litigis contra els estats relatius a les conseqüències de l'escalfament global, és més freqüent — més de vuit-cents litigis plantejats en els darrers anys en més d'una vintena de països $-{ }^{14} \mathrm{i}$ té més ressò mediàtic. Un bon exemple en són el casos recents plantejats per l'associació Urgenda contra els Països Baixos per l'incompliment dels compromisos de reducció de les emissions $\mathrm{GEH}^{15}$ i per Greenpeace contra Noruega per la concessió de noves llicències d'explotació dels hidrocarburs al mar de Barent ${ }^{16}$.

\footnotetext{
${ }^{12}$ Doc. FCCC/SBSTA/2017/L.29.

${ }^{13}$ Petició a la Comissió Interamericana de Drets Humans pels danys originats per l'escalfament global causat per actes i omissions dels Estats Units (7 de desembre de 2005), petició núm. P-1413-05.

${ }^{14}$ United Nations Environment Programme, The Status of Climate Change Litigation - A Global Review, 2017, disponible en línia a $<$ http://columbiaclimatelaw.com/files/2017/05/Burger-Gundlach-2017-05-UNEnvt-CC-Litigation.pdf $>$, p. 10.

${ }^{15}$ Sentència de la Cort de Districte de la Haia de 24 de juny 2015, Urgenda Foundation c. Països Baixos, versió en anglès disponible en línia a $<$ http://www.urgenda.nl/documents/VerdictDistrictCourtUrgendavStaat-24.06.2015.pdf>.

${ }^{16}$ Demanda davant de la Cort de Districte d'Oslo de 18 d'octubre 2016, Greenpeace Nordic Association c. Govern de Noruega, versió en anglès disponible en línia a $<$ http://blogs2.law.columbia.edu/climatechange-litigation/wp-content/uploads/sites/16/non-us-casedocuments/2016/20161018_3593_petition.pdf $>$.
} 
L'Acord de París, juntament amb el Protocol, emergeixen com una possible base per a aquesta acció, especialment per la vinculació entre l'obligació d'executar els compromisos assumits per part dels estats (pre-2020 i post-2020) i la manca de mecanismes coercitius en casos d'incompliment $i$ la impossibilitat de retrocedir en el nivell d'ambició en l'assoliment de l'objectiu de limitar l'escalfament del planeta als $2^{\circ} \mathrm{C}$. Constitueix, per tant, una mostra que el problema del canvi climàtic no té només una resposta de dimensió predominantment internacional, sinó que l'acció contra aquest fenomen té també, cada vegada més, una important vessant nacional, regional i local. 